\title{
COMMENT
}

\section{Equity culture in pediatrics}

\author{
Elena Fuentes-Afflick ${ }^{1}$ \\ Pediatric Research (2022) 91:1639-1640; https://doi.org/10.1038/s41390-020-01295-4
}

Around the world and within the hallowed halls of medicine, we stand on the precipice of transformational change. ${ }^{1,2}$ As a global community, we have been rocked by three intersecting crises: the coronavirus disease 2019 (COVID-19) pandemic, the global demand for racial justice, and the existential challenge of climate change. Although the COVID-19 pandemic has not affected children as much as adults, the persistent scourge of racial injustice affects pediatric patients and their families and the adverse health effects of climate change will undoubtedly affect children. I believe we have reached a critical moment in which we must take intentional, collective action to create culture change. At this critical juncture, we have the opportunity to commit ourselves to equity culture. In every aspect of our professional work, whether clinical care, education and training, research scholarship, mentoring, or service, there is a dimension of equity that must be identified, addressed, and transformed.

American culture has many strengths as well as longstanding flaws. Racial injustice is deeply embedded in American society ${ }^{3}$ and eradication will require innovative, widespread societal action. Nonetheless, the global call for transformative change is loud and clear. It is painful to acknowledge that racism is embedded within academic medicine, ${ }^{2}$ including pediatrics, but we must commit to change. ${ }^{4}$ In a recent issue of the Journal, four senior members of the academic pediatric community engaged in a webinar focused on these topics, "APS/SPR Virtual Chat: Race, Racism, and Child Health Equity in Academic Pediatrics." ${ }^{5}$ Using a series of questions to elicit personal reflections and promote conversation regarding race, racism, and equity, the authors highlight the challenge and outline concrete actions for us to consider.

The National Academies of Science, Engineering and Medicine's 2017 report, Communities in Action: Pathways to Health Equity, defines health equity as "the state in which everyone has the opportunity to attain full health potential and no one is disadvantaged from achieving this potential because of social position or any other socially defined circumstance." ${ }^{\prime \prime}$ To achieve health equity in pediatrics, we must make a shared commitment and then embark on a complex, multifaceted series of strategies and tactics to achieve the goal. Creating equity culture will affect our interpersonal relationships, our professional work habits, and our institutional culture. One way to start the process is through sharing personal stories. ${ }^{5}$ However, it is important to remember that one person represents only herself and is not responsible for explaining or demystifying any aspect of her characteristics to others. As Dr. Coker and Dr. Keller noted, ${ }^{5}$ it takes courage to engage in conversations about race and racism. Despite hesitation or concern, I believe that now is the right time for contagious courage. When one person engages in conversation, others may be inspired to follow.
However, conversation about race and racism can be very sensitive, painful, and may trigger strong emotional responses. Dr. Coker and Dr. Keller invite us to engage in conversation, even at the risk of making mistakes. ${ }^{5}$ We may need to ask for "forgiveness in advance" or be prepared to give or receive difficult feedback, but I hope that we will become more effective over time. Although we are trained to avoid making mistakes, the path toward health equity and creation of equity culture will undoubtedly include unintentional mistakes, which we must learn to interpret as developmental steps toward improvement.

Creation of equity culture will require engagement and change at multiple levels. Over the past 10 years, pediatric societies have increasingly focused on diversity, equity, and inclusion., ${ }^{78}$ Recently, the American Academy of Pediatrics issued a bold statement that highlighted the impact of racism on child health and articulated the Academy's commitment to addressing racism. ${ }^{9}$ Initiatives such as the virtual chat sponsored by the American Pediatric Society and the Society for Pediatric Research ${ }^{5}$ represent another opportunity for organizational engagement. I hope that we will continue to use our annual meeting to amplify our education regarding equity, diversity, and inclusion and that we will find ways to engage the entire pediatric community. Our academic institutions must be engaged in the effort to promote equity and pediatric department chairs and division chiefs should play essential roles.

Within the field of pediatrics, I believe we have some advantages as compared to other medical disciplines. First, we are generally optimists. When we care for our patients and when we teach our learners, we are supporting the next generation, demonstrating our faith that the future can be better, and we embrace the opportunity to shape the future. Second, our students and residents push us forward and motivate us to interpret the relationship between our everyday work and broad societal issues. As noted by Dr. Chase Anderson, a psychiatry resident, "What is my role, as a physician, in advocating for a better world outside the hospital? And what can I actually do?"10 At present, however, it is not clear which interventions are most effective to advance health equity. ${ }^{1,2}$ We need more research to develop and test interventions to address the challenges of racism in pediatrics. ${ }^{11}$

Despite the lack of evidence-based approaches to advance equity culture, we can begin to act, using "The 5 Ls" (Table 1). The first $L$ is "look"-look around at what is happening and engage in a regular habit of reflection. Regardless of our own background, we must become effective allies and "[look] beyond the perceived interests of one's own group and [recognize] the common benefit of dismantling a system of belief and practice that privileges some racial groups over others." ${ }^{4}$ A second dimension of the word "look" is to look inside yourself and reflect on your experiences 
Table 1. The 5 Ls of equity culture.

Look

Listen

Lean

Lend

Lead

with equity, how your perception and experiences have changed, and decide whether you are prepared to change in ways that advance health equity. The second $L$ is "listen." As demonstrated by Dr. Keller and Dr. Coker, we must actively engage in listening to others, from their perspective. ${ }^{5}$ The third L is "lean," meaning lean into the process. Leaning in may include speaking with colleagues about race and racism; leaning into an interpersonal encounter to advance equity or pursuing a new type of research; and developing new curricula or new clinical programs that address equity, diversity, and inclusion. The fourth $L$ is "lend," meaning to lend a hand, lend an ear, or lend your voice. We know that our students and trainees observe how we interact and how our actions uphold our values. Thus, if we encounter an inequitable situation and choose not to intervene, our actions can have lasting impact. ${ }^{1}$ The fifth $\mathrm{L}$ is "lead" because we are all leaders in this effort. No matter who you are or where you are in your professional career, every day presents the opportunity to advance equity culture. Some individuals are charged with the responsibility of implementing programs and initiatives related to equity but each of us has the opportunity to act in support of the greater goal.

The pursuit of health equity and the creation of equity culture are inspiring, evolving goals and it will be challenging to know when we have achieved success. ${ }^{12}$ Nonetheless, we must accept that this endeavor involves all of us and "you must believe that this fight is your own." ${ }^{4}$ Working individually and collectively and wholeheartedly embracing the challenge of the global call for racial equity, we can create and implement equity culture in pediatrics.

\section{ADDITIONAL INFORMATION}

Competing interests: The author declares no competing interests.

Publisher's note Springer Nature remains neutral with regard to jurisdictional claims in published maps and institutional affiliations.

\section{REFERENCES}

1. Acosta, D. \& Ackerman-Barger, K. Breaking the silence: time to talk about race and racism. Acad. Med. 92, 285-288 (2017).

2. Yancy, C. W. Academic medicine and Black lives matter: time for deep listening. JAMA 324, 435-436 (2020).

3. Dreyer, B. P. et al. The death of George Floyd: bending the arc of history toward justice for generations of children. Pediatrics 146, e2020009639 (2020).

4. Jeung, J. \& Heard-Garris, N. To be an ally, you must believe the fight for racial justice is your fight. AAP News 24 (2020).

5. Coker, T., Keller, D., Davis, S. \& Abman, S. APS/SPR Virtual Chat: race, racism, and child health equity in academic pediatrics. Pediatr. Res. https://doi.org/10.1038/ s41390-020-01176-w (2020).

6. National Academies of Science, Engineering, and Medicine, Health and Medicine Division, Board on Population Health and Public Health Practice \& Committee on Community-Based Solutions to Promote Health Equity in the United States. Communities in Action: Pathways to Health Equity (The National Academies Press, Washington, DC, 2017).

7. Fuentes-Afflick, E. American Pediatric Society 2018 Presidential Address - the courage of our dreams. Pediatr. Res. 84, 582-585 (2018).

8. Stapleton, F. B. American Pediatric Society 2012 Presidential Address: mind the gap. Pediatr. Res. 72, 441-443 (2012).

9. Trent, $M$. et al. The impact of racism on child and adolescent health. Pediatrics 144, e20191765 (2019).

10. Anderson, C. T. M. Taking back our voices=\#HumanitylsOurLane. N. Engl. J. Med. 383, 1609-1611 (2020).

11. Johnson, T. et al. Implicit bias in pediatric academic medicine. J. Natl Med. Assoc. 109, 156-163 (2017).

12. Montoya-Williams, D., Pena, M.-M. \& Fuentes-Afflick, E. In pursuit of health equity in pediatrics. J. Pediatr. X 5, 100045 (2020). 